\title{
Saude suplementar no Brasil: \\ o papel da Agência Nacional de Saúde Suplementar na regulação do setor
}

\author{
| ' Louise Pietrobon, ${ }^{2}$ Martha Lenise do Prado, ${ }^{3}$ João Carlos Caetano |
}

Resumo: Este artigo procurou contextualizar a saúde suplementar no Brasil, bem como a estruturação e a regulação do setor, utilizando uma análise da literatura e uma visão crítica sobre o assunto. A construção de um sistema de saúde suplementar acarretou disputas entre os diferentes setores envolvidos e o avanço ocorreu ao longo de muitos anos, culminando na criação da Agência Nacional de Saúde Suplementar (ANS) e sua posterior implementação. À ANS coube promover a defesa do interesse público na assistência suplementar à saúde e regular as operadoras setoriais, inclusive em suas relaçôes com os prestadores de serviço e consumidores, contribuindo para o desenvolvimento das ações de saúde. Com o número de beneficiários ultrapassando os 40 milhōes, a ANS é uma realidade e uma necessidade no setor no Brasil. A ANS possui excelentes possibilidades com a criaçẫo, verificação e divulgação de indicadores da qualidade da promoção e dos cuidados integrais da saúde, e a busca pela qualificação das operadoras de seguros de saúde impulsiona a regulação. Por outro lado, há uma necessidade premente de que a ANS atue mais diretamente nas relaçōes conturbadas entre as operadoras de planos de saúde, os prestadores de serviços e os beneficiários mediando as tensōes e contribuindo ativamente para a melhoria do sistema de saúde como um todo.
${ }^{1}$ Doutoranda da PósGraduação em Odontologia da Universidade Federal de Santa Catarina, área de concentração Odontologia em Saúde Coletiva.

Endereço eletrônico: isepietro@terra.com.br.

2 Professora Doutora da PósGraduação em Enfermagem da Universidade Federal de Santa Catarina.

${ }^{3}$ Professor Doutor da PósGraduação em Odontologia da Universidade Federal de Santa Catarina.
Recebido em: 13/11/2007. Aprovado em: 20/08/2008. 


\section{Introdução}

O atual sistema de saúde no Brasil está sedimentado na premissa da Constituição Federal de 1988, que expressa a saúde como um direito de todos os brasileiros, cabendo ao Estado cuidar da assistência pública, da edição de normas de proteção à saúde e da prestação de assistência médica e hospitalar mediante políticas sociais e econômicas. Esse sistema de saúde pode ser dividido em dois subsistemas: o público e o privado (BRASIL, 2007).

O subsistema público é representado pelo Sistema Único de Saúde (SUS), que é um sistema universal de saúde com financiamento público e participação das esferas da federação, gestão pública, única, com integração e articulação entre as diferentes esferas e a prestação de assistência, através de serviços de rede própria de municípios, estados e União, de serviços públicos de outras áreas de governo e de serviços privados contratados ou conveniados (BRASIL, 2007).

A implantação do SUS significou a extensão de assistência médico-sanitária a expressivos contingentes de brasileiros. Entretanto, segundo Acioli (2006), para a população brasileira as consolidações de um valor de uso e a legitimação social do SUS ainda estão longe de acontecer. Então, o acesso aos serviços de saúde públicos está aberto a todos os brasileiros, não mais importando sua situação empregatícia ou legal, mas ainda existe uma longa caminhada para que toda a população realmente usufrua dos serviços de saúde de maneira completa e integral. Ainda segundo o autor, embora haja uma gratuidade direta quando do acesso e utilização dos serviços ofertados pelo SUS, o desembolso é feito de forma indireta, através do pagamento dos impostos.

O subsistema privado é dividido em dois subsetores: o subsetor saúde suplementar e o subsetor liberal clássico. O liberal clássico é o composto por serviços particulares autônomos, caracterizados por clientela própria, captada por processos informais, em que os profissionais da saúde estabelecem diretamente as condições de tratamento e de sua remuneração. A saúde suplementar é composta pelos serviços financiados pelos planos e seguros de saúde, sendo predominante neste subsistema. Este possui um financiamento privado, mas com subsídios públicos, gestão privada regulada pela Agência Nacional de Saúde Suplementar. Os prestadores de assistência são privados, credenciados pelos planos e seguros de saúde ou pelas cooperativas médicas, serviços próprios dos planos e seguros de saúde, serviços conveniados ou contratados pelo subsistema 
público, que são contratados pelas empresas de planos e seguros de saúde que fazem parte de sua rede credenciada (BRASIL, 2007).

O setor de planos de saúde é definido como suplementar, no Brasil, devido à opção de se pagar um seguro privado para ter acesso à assistência médica, a despeito da manutenção da contribuição compulsória para a seguridade social, que inclui o direito ao acesso ao serviço público (BAHIA, 2001). Por outro lado, poderia ser classificado de complementar, e por vezes o é, quando supõe a existência e a limitação do sistema de saúde público - neste caso, o sistema privado complementa a cobertura de determinados serviços.

De forma sintética, Acioli (2006) exprime a definição entre os subsistemas público e privado, em que a estruturação do SUS produz a ampliação das demandas e reorganização da oferta de serviços de saúde, aprofundando a crise estrutural da economia do país. Esta questão traz o movimento político que exige a regulação do sistema privado de atenção à saúde e a definição do caráter, mais complementar ou mais suplementar, da relação que tem o sistema privado em relação ao SUS. De certa forma, os subsídios fiscais do Estado para o subsistema privado, os gastos com a saúde suplementar dos funcionários federais, bem como com os gastos tributários das renúncias fiscais, impedem que o SUS receba maior financiamento. De acordo com o IDEC (2007), esse padrão de financiamento foi herdado do regime militar e foi ampliado com o passar dos anos.

Portanto, a atenção à saúde é exercida fundamentalmente no Brasil pelo Sistema Único de Saúde e deveria garantir a saúde nos termos de eqüidade, universalidade e igualdade. Entretanto, o setor público vem continuamente expondo suas iniqüidades, que, submetidas a constantes críticas e inequívocos exemplos de ineficiência, serviram como grande atrativo para os planos de saúde privados ampliarem sua atuação no mercado (SILVA, 2003).

Isso é evidenciado pela expansão significativa da saúde suplementar nas últimas décadas, estimando-se, segundo os dados da PNAD/98, em 38,7 milhōes o número de brasileiros cobertos por pelo menos um plano de saúde, o que corresponde a $24,5 \%$ da população do País (IBGE, 2000). Segundo o PNAD/2003, esse número elevou-se para 43,2 milhões de pessoas, correspondendo a $24,6 \%$ da população. 


\section{Regulação}

Existem muitas conceituações para regulação, e cada uma demonstra a perspectiva e o valor de quem as elabora e as utiliza. Regular também tem como significados: sujeitar-se a regras, dirigir, regrar, encaminhar conforme a lei, esclarecer e facilitar por meio de disposições, regulamentar, estabelecer regras para regularizar, estabelecer ordem ou parcimônia em, acertar, ajustar, conter, moderar, reprimir, conformar, aferir, confrontar, comparar, dentre outros, de acordo com o dicionário Aurélio.

Segundo o livro Regulação em Saúde (2007), a regulação é realizada através de intervenção do governo, por meio de regras, leis e normas, no mercado de prestação de serviços de saúde ou no sistema de saúde. Incorpora uma grande variedade de mecanismos, além de incentivos positivos e negativos. Essa função regulatória pode ter várias formas, como a definição de arcabouço legal, a regulação da competitividade, os parâmetros mínimos e de excelência e, em particular, as várias formas de incentivo financeiro.

Regulação ocorre quando o governo controla ou deliberadamente influencia determinada atividade, pela manipulação de variáveis como preço, quantidade e qualidade. Dessa forma, é necessário ter em mente o significado da regulação; é preciso sempre manter foco no objetivo, que é assegurar o desempenho do sistema de saúde, ou seja, prestar uma assistência eficiente e eqüitativa e atender às necessidades de saúde da população.

\section{A regulamentação da saúde suplementar}

No Brasil, a saúde suplementar começou sua estruturação após a revolução industrial, momento em que surgiram os Institutos de Aposentadorias e Pensões (IAPs), que pertenciam a diversas categorias e representavam os trabalhadores urbanos e que compravam as prestações de serviços de saúde. Paralelamente, nos anos 40, apareceram também as Caixas de Assistência, como a dos funcionários do Banco do Brasil (Cassi), que beneficiavam os empregados de algumas empresas por meio de empréstimos ou reembolso pela utilização de serviços de saúde externos à previdência social.

Nos anos 50, surgem os sistemas assistenciais próprios fornecidos pelas empresas estatais e multinacionais que prestavam assistência médica de forma direta. Os IAPs, no ano de 1966, são então unificados, formando o Instituto Nacional de 
Previdência Social (INPS). Essa unificação forçou a expansão dos credenciamentos de prestadores de serviços privados de saúde, privilegiando hospitais e multinacionais de medicamentos. Portanto, a década de 60 foi um marco na história da saúde suplementar, pelo fato de boa parte dos trabalhadores já possuir planos de saúde e, ainda, por serem observadas diversas possibilidades de assistência médica: a rede INPS, com unidades próprias e credenciadas; serviços credenciados para atendimento a trabalhadores rurais; serviços credenciados das empresas médicas; e autogestôes de empresas com planos próprios. Todas essas possibilidades ofereciam a mesma cobertura para todos os empregados independentemente do nível hierárquico na empresa.

Na década de 70 foi criado o Sistema Nacional de Previdência e Assistência Social (SINPAS), da qual fazia parte o Instituto Nacional de Assistência Médica e Previdência Social (INAMPS), que privilegia ainda mais a compra de serviços do setor privado, provocando uma capitalização crescente deste setor. A década de 80 é marcada por crises políticas, sociais e econômicas e, ainda, cresce o movimento sanitário brasileiro, que culmina na criação do SUS e na manutenção e ampliação do setor suplementar (RONCALLI, 2003).

O modelo de regulação do setor de saúde suplementar brasileiro é diferenciado em relação à experiência internacional. Na maioria dos países, a regulação é feita a partir da atividade econômica em si, atuando sobre as empresas do setor e garantindo suas condições de solvência e a competitividade do mercado. No Brasil, optou-se por regular fortemente o produto oferecido, ou seja, a assistência à saúde, com medidas inovadoras como a proibição da seleção de risco e do rompimento unilateral dos contratos. E a regulação tinha como objetivos principais corrigir as distorções quanto às seleções de risco e preservar a competitividade do mercado (BAHIA; VIANA, 2002).

Essa regulação do setor de saúde suplementar surgiu após mais de 30 anos de operações sem controle do governo. Em período anterior a 1998, os consumidores passaram a ser mais protegidos, com a adoção do Código de Defesa do Consumidor, que trouxe a estrutura jurídica que deve nortear as relações de consumo (SALAZAR et al., 2005), e com a atuação nos Procons estaduais e municipais. O acolhimento de demandas pelos Procons beneficiou os consumidores em seus conflitos com as operadoras de planos de saúde. No entanto, a atuação desses organismos estatais mostrou-se insuficiente para regular as relaçôes entre consumidores e operadoras. 
Houve a necessidade de intervenção estatal, visando a corrigir e atenuar as falhas do mercado, como as exclusões de atendimento e as mensalidades abusivas, e somente após a promulgação da Lei no 9.656/98, o setor de saúde suplementar ganhou a sustentação legal para que se iniciassem as ações de regulamentação (SILVA, 2003).

Segundo Salazar et al. (2005), apesar de a proteção aos beneficiários de planos de saúde apresentar avanços, a Lei no 9656/98 não resolveu os principais conflitos entre os beneficiários e as operadoras, e de certa forma pareceu desobrigar o setor privado de obedecer à Lei Orgânica da Saúde. Então a regulamentação do setor de saúde suplementar, exigida pela Constituição de 1988, surge apenas em 1998, quando o SUS já apresentava no mínimo cinco importantes marcos em seu processo de construção: a Lei Orgânica da Saúde, Lei no 8.080/90, a extinção do INAMPS, as Normas Operacionais Básicas (NOB/93 e NOB/96) e a implantação do Piso da Atenção Básica (PAB) em 1998 (BRASIL, 2003).

Como marco legal do processo de regulação, portanto, entende-se o conjunto formado pela Lei no 9.656/98 e a Medida Provisória (MP), que à época tomou a numeração 1.665. Esta MP, republicada várias vezes, leva atualmente o número 2177-44. Ao conjunto Lei + MP foi acrescido, em janeiro de 2000, a Lei $\mathrm{n}^{\circ}$ 9.961, que criou a ANS e lhe deu as atribuições de regulação do setor. A regulamentação, que mediante a Lei no 9.656/98 teve início, aprofundou-se com a Lei no 9.961/00, que criou a Agência Nacional de Saúde Suplementar (ANS), mas ainda existe um grande percurso na sua consolidação (BRASIL, 1998; 2000a; SALAZAR et al., 2003).

Neste momento, convive-se com uma grande heterogeneidade nos padrões de qualidade do setor, fragmentação e descontinuidade da atenção que comprometem a efetividade e a eficiência do sistema como um todo, atingindo as redes de cuidados básicos, especializados e hospitalares, que atendem à clientela de planos de saúde.

\section{Situação atual do mercado de saúde suplementar}

Segundo Duarte (2001, p. 367), “o sistema de atenção médica suplementar cresceu a passos largos durante a década de 80, de tal modo que, em 1989, cobria $22 \%$ da população total do país. Somente no período $1987 / 89$ incorporaram-se a esse subsistema 7.200.000 beneficiários”. Atualmente, o número de usuários registrados na ANS é de aproximadamente 45,9 milhões de 
beneficiários no total de vínculos a planos de assistência médica com ou sem odontologia e planos exclusivamente odontológicos (ANS, 2007).

Segundo o Guia de Análise Econômica de Atos de Concentração Horizontal do Conselho Administrativo de Defesa Econômica (Cadê), um mercado é concentrado quando a maior empresa detém mais de $20 \%$ do faturamento ou quando esse percentual é acima de $75 \%$ para as quatro maiores empresas. Deste ponto de vista, o mercado brasileiro na sua totalidade não apresenta concentração em nenhum dos segmentos (total, médico-hospitalar e odontológico). Apesar de possuir aproximadamente 200 operadoras, detém $80 \%$ do mercado e $95 \%$ dos consumidores de planos de saúde estão localizados na área urbana, sendo que 77\% na Região Sudeste do país, principalmente em São Paulo e Rio de Janeiro (BRASIL, 2003).

Entretanto, quando se observam as operadoras localmente, ou seja, no seu local de competição por mercado, há concentração em 23 das 27 unidades da federação entre as operadoras que comercializam planos odontológicos, com a maior empresa detendo mais de $20 \%$ dos beneficiários. Entre as operadoras médicohospitalares, a concentração está presente em 18 estados (ANS, 2007). Esses dados são confirmados por Reis (2007), que expõe que em março de 2006 apenas oito operadoras detinham $21 \%$ dos usuários dos planos de saúde, o equivalente a 7,6 milhões de planos de assistência médica.

Segundo Alfredo Scaff, no Encontro da ANS com as Operadoras de Planos de Saúde, em maio de 2007, o fato de existirem 2.080 operadoras ativas, ou seja, com beneficiários, torna o mercado da saúde suplementar concorrencial. Por outro lado, torna-se necessário repensar e construir modelos de atenção à saúde sob novas bases para aumentar a eficiência, através da otimização de gastos segundo as necessidades; aumentar a eficácia, aumentando e qualificando os resultados; e aumentar a efetividade, contribuindo mais para uma melhoria da saúde.

Confirmando essa vontade, o diretor presidente da ANS, Dr. Fausto Pereira dos Santos, nos afirma que a aposta da atual gestão da ANS é:

construção de um setor da saúde suplementar cujo principal interesse a produção de saúde. Um setor que seja centrado no usuário, que realize ações de promoção de saúde e prevenção de doenças, que observe os princípios de qualidade, integralidade e resolutividade, que tenha uma concepção includente de todos os profissionais de saúde, que respeite o controle social, que esteja completamente articulado com o Ministério da Saúde e cujo o órgão regulador seja também preocupado com a qualificação de seu processo regulatório. (SCAFF, 2007, s/p). 
Assim, desde que o sistema privado de atenção à saúde foi regulamentado, em 1988, com a publicação da Lei no $9.656 / 98$ e suas sucessivas alterações, além da implantação da ANS, as empresas operadoras têm procurado se ajustar e se enquadrar aos padrões e normas estabelecidas, visando a um equilíbrio financeiro interno e à satisfação de seus usuários e prestadores de serviços. Essa tarefa não tem sido fácil, tendo em vista os desafios e exigências impostos pela agência reguladora.

A implantação da ANS auxilia na regulação do setor de saúde suplementar. Essa regulação acontece e é apenas utilizada para os planos individuais e limitada aos planos pós 1999. Reis (2007) enfatiza que, se a ANS continuar regulando apenas os planos individuais, pode-se perder o sentido da Agência e há necessidade de ampliação da regulamentação consolidando ações regulatórias na interface público-privado. Essa ampliação é necessária quando se observa que a maior parte $(74,9 \%)$ dos planos de saúde comercializados no Brasil situa-se na modalidade coletiva (ANS, 2008) e que esses são adquiridos pelas empresas em geral, diferindo apenas no seu modo de aquisição, sendo voluntária ou compulsória, e em muitos casos com existência de co-pagamento.

A ANS (2008) afirma que nessa modalidade coletiva de planos de saúde não existe uma necessidade de regulação da mesma maneira que na modalidade individual, pois como os contratos são estabelecidos pelas operadoras e pelas empresas empregadoras, podem-se negociar os valores dos contratos dependendo do número de funcionários que serão contemplados com os planos de saúde, o que, segundo a ANS, possibilita que o próprio mercado regule os preços. Por outro lado, o IDEC (2007) referencia que os planos de saúde com contratos coletivos, por não estarem sob a atuação da ANS, sofrem reajustes de preços sem previsão e/ ou por sinistralidade e cancelamentos de contrato unilateralmente, bem como restrições de contrato devido ao desligamento da empresa.

Silva (2003, p.36) relata que na relação das operadoras e prestadores de serviço, "o nível de desconfiança e de desequilíbrio da relação é tão forte que, com um cenário desastroso sendo continuamente desenhado por ambas as partes, cada uma delas acredita que o outro negócio deva ser melhor que o seu."

$\mathrm{Na}$ tentativa de ajustar essas relações, em 2007 todas as empresas operadoras deverão implantar o novo Plano de Contas estabelecido pela ANS, além de ajustarem suas reservas técnicas. Haverá, ainda, a implantação da Troca de Informações de 
Saúde Suplementar (TISS), que padronizará as guias preenchidas nos diversos prestadores de serviços médicos e odontológicos; e a instituição do Programa de Qualificação, cujo principal interesse é a produção da saúde, com a realização de ações de promoção à saúde e prevenção de doenças, como parte de um investimento humano e tecnológico que cada empresa deverá dispor em curto prazo.

Segundo notícia publicada no site da ANS em 03/10/2007, a Agência, através do Programa de Qualificação da Saúde Suplementar, qualificou 1.123 operadoras de um total de 2.000 que enviaram formulários no ano de 2006. Essas operadoras responderam a 40 milhōes de beneficiários, ou seja, 92\% do total do Brasil, evidenciando uma melhoria na qualidade da regulação do setor de saúde suplementar, seja pelo aumento do número de operadoras qualificadas em relação ao ano de 2005 (que foi 906 de um total de 2.048), seja pelo fato de essas empresas responderem pela maioria dos beneficiários.

Por outro lado, para atender às necessidades da Agência e aquelas atreladas a uma redução de custos administrativos associada à economia de escala, algumas empresas, sobretudo as localizadas nos grandes centros urbanos, estão se fundindo, sendo incorporadas ou até mesmo abrindo seu capital, lançando ações na Bolsa de Valores, para uma rápida capitalização. Já as operadoras de pequenas localidades onde operam isoladamente e não têm o risco da eminente concorrência, deverão unir forças, por meio de suas entidades representativas, a fim de garantir o acesso às informações e à troca de experiências (ANS, 2007).

Frente a isso, Reis (2007) levanta a hipótese de que as empresas líderes criaram um cerco à política regulatória da ANS, pressionando o reajuste de preços dos planos individuais antigos. Isso se evidencia através do resguardo oferecido às operadoras por determinação do Supremo Tribunal Federal, que estabeleceu que os planos de saúde, denominados antigos, de ocorrência anterior à criação da Agência, não podem ser submetidos a sua regulamentação.

\section{O papel da Agência Nacional de Saúde Suplementar}

A Agência Nacional de Saúde Suplementar (ANS) é uma autarquia sob regime especial vinculada ao Ministério da Saúde e responsável pela regulação, normatização, controle e fiscalização das atividades que garantam a assistência suplementar à saúde. Tem por finalidade institucional "promover a defesa do interesse público na assistência suplementar à saúde, regulando as operadoras 
setoriais, inclusive quanto às suas relações com prestadores e consumidores, contribuindo para o desenvolvimento das ações de saúde” (BRASIL, 2000).

A ANS possui maior poder de ação, autonomia administrativa, financeira e política, em relação ao governo, expressas por uma arrecadação própria e decisões da Diretoria Colegiada com poder legal para efetivar suas resoluçóes. Possui, ainda, competência de polícia normativa, decisória e sancionária exercida sobre qualquer modalidade de produto, serviço e contrato que apresente, além da garantia de cobertura financeira de riscos de assistência médica, hospitalar e odontológica, outras características que diferenciem de atividades exclusivamente econômicofinanceiras (LIMA, 2007).

A ANS está organizada em cinco áreas:

1. Diretoria de Normas e Habilitação das Operadoras: responsável pela normatização, registro e monitoramento do funcionamento das operadoras, inclusive intervenção e liquidação;

2. Diretoria de Normas e Habilitação de Produtos: responsável pela normatização, registro e monitoramento dos produtos, inclusive reajuste de planos individuais e familiares;

3. Diretoria de Fiscalização: responsável por todo o processo de fiscalização, aspectos econômico-financeiros, médicos assistenciais, apoio ao consumidor e articulação com seus órgãos de defesa;

4. Diretoria de Desenvolvimento Setorial: responsável pelo sistema de ressarcimento do SUS e pelo desenvolvimento de instrumentos que viabilizem a melhoria da qualidade e o aumento da competitividade do setor; e

5. Diretoria de Gestão: responsável pelo gerenciamento de recursos humanos e financeiros, suprimentos, informática e informação.

Os objetivos básicos e as estratégias diferenciadas de implementação da regulamentação surgem claramente do marco regulatório e evoluem a partir da ampliação do conhecimento sobre o setor de saúde suplementar. Os objetivos da regulamentação podem ser resumidos em seis pontos: 1) assegurar aos consumidores de planos privados de assistência à saúde cobertura assistencial integral e regular as condições de acesso; 2) definir e controlar as condições de ingresso, operação e saída das empresas e entidades que operam no setor; 3) definir e implantar mecanismos de garantias assistenciais e financeiras que assegurem a continuidade da prestação de serviços de assistência à saúde contratados pelos consumidores; 4) 
dar transparência e garantir a integração do setor de saúde suplementar ao SUS e o ressarcimento dos gastos gerados por usuários de planos privados de assistência à saúde no sistema público; 5) estabelecer mecanismos de controle da abusividade de preços; 6) definir o sistema de regulamentação, normatização e fiscalização do setor de saúde suplementar (BRASIL, 2003).

As competências estabelecidas pela Resolução RDC no 1 da ANS são:

- estabelecer critérios de aferição e controle da qualidade dos serviços oferecidos pelas operadoras de planos privados de assistência à saúde, sejam eles próprios, referenciados, contratados ou conveniados;

- expedir normas e padrões para o envio de informações de natureza econômico-financeira pelas operadoras, com vistas à homologação de reajustes e revisões;

- proceder à integração de informações com os bancos de dados do SUS;

- requisitar o fornecimento de quaisquer informaçóes das operadoras de planos privados de assistência à saúde, bem como da rede prestadora de serviços a elas credenciados.

A ANS desenvolve e aprimora inúmeros mecanismos para gerar informações relativas ao setor de saúde suplementar: a constituição de câmaras técnicas; consultas públicas; disque-ANS e portal ANS; e o acesso através dos núcleos regionais. Para as ações de fiscalização, existem dois grandes blocos de atuações estratégicas: medidas preventivas e os regimes especiais. As medidas preventivas são os processos de ajuste acordados entre a ANS e as operadoras de planos de saúde e os planos de recuperação. Os regimes especiais são as direções técnicas e fiscais que são processos instaurados pela ANS quando as empresas descumprem os processos de ajuste e realizam processos de monitoramento das anormalidades administrativas (BRASIL, 2007; LIMA, 2007). A ANS desenvolve, ainda, dois projetos para a fiscalização e instrumentos de transformação de comportamento do mercado de planos de saúde denominados "Cidadania Ativa" e "Olho Vivo" (LIMA, 2007).

Segundo o Conselho Nacional dos Secretários de Saúde (CONASEMS, 2007), a instituição da ANS possibilitou um maior conhecimento do setor e a definição de critérios para a entrada no mercado, funcionamento e acompanhamento econômico-financeiro das operadoras de planos e seguros de saúde (BRASIL, 2007). A fiscalização visa, também, a impedir que operadoras inescrupulosas desprezem os direitos e os interesses dos beneficiários e obtenham vantagens sobre estes. $\mathrm{O}$ 
aumento desta fiscalização - regulação - causou conseqüente aumento da visibilidade dos problemas estruturais e dos desequilíbrios existentes no setor da saúde suplementar. Essa fiscalização não precisa ser unicamente exercida pela ANS, apesar de sua legitimidade e competência, e pode ser auxiliada pelos Procons, que possuem atividades estaduais e municipais, bem como por outros órgão privados como as experiências de auto-regulação (LIMA, 2007).

Pode-se afirmar e observar, na figura 1, que existem dois campos de regulação: o campo A sendo a macrorregulação realizada pela legislação de regulamentação; o campo B sendo a autorregulação realizada pelos atores do sistema, operadoras, prestadores e beneficiários, constituindo o mercado de seguros de saúde privados propriamente dito. A ANS está centrada, principalmente, na regulação do campo A; entretanto, há necessidade de que o Estado representado pela ANS se torne ativo no campo B, para que exerça o papel regulador e mediador das tensões e disputas existentes entre os atores (MALTA et al., 2004).

\section{Figura 1: A regulação da ANS}

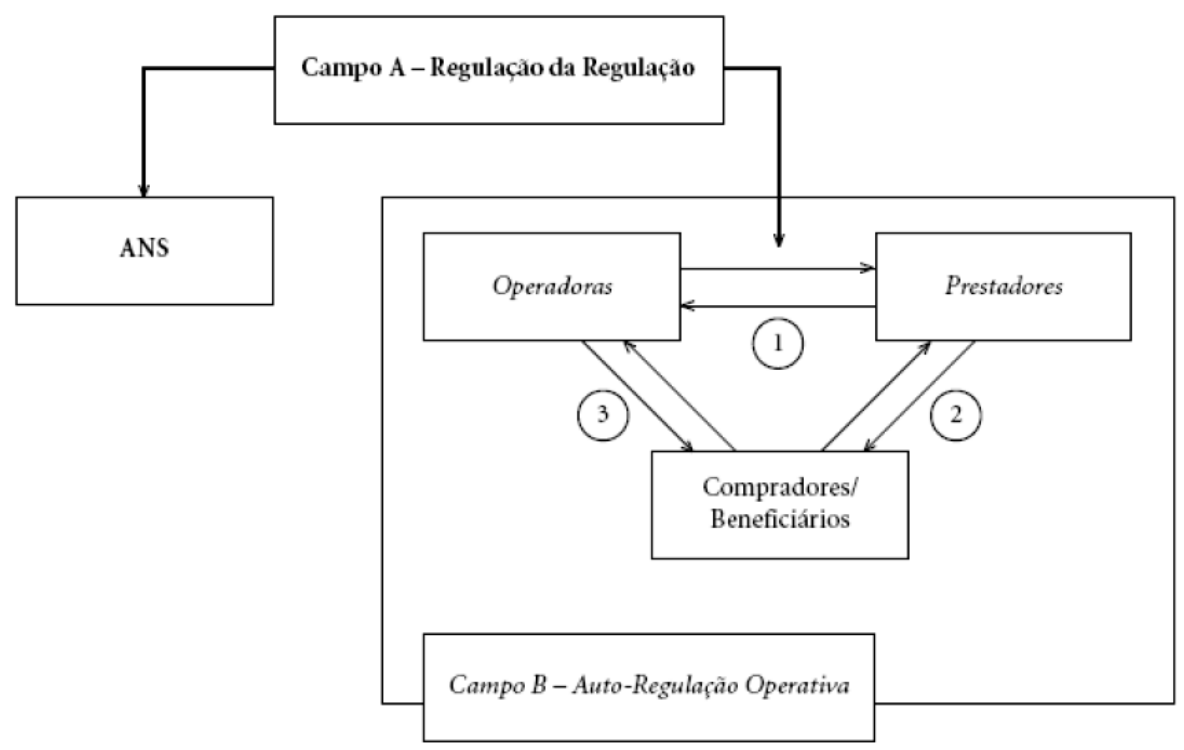

Fonte: Cecílio et al. (2005). 
Malta et al. (2004) identificam três ênfases na atuação da ANS: 1) a regulação financeira das operadoras; 2) o direito dos consumidores, contratos e relações de consumo; e 3) nos produtos visando ao controle do preço da assistência à saúde. Devido a essa prática fragmentada na regulação do setor, a produção de saúde encontra-se em seus estágios iniciais. Entretanto, segundo Cecílio et al. (2005), a ANS tem vivido um "ímpeto regulatório" por causa da regulamentação recente e por a ANS ainda se encontrar em processo de autoconstituição. Há também o fato de a regulação de planos privados de saúde ser um território político no qual há sempre inconciliáveis e conflitantes interesses.

A decisão de delegar as tarefas regulatórias ocasiona riscos e custos para os políticos. Segundo Pereira (2007), é surpreendente que o Brasil tenha optado por esse modelo, em vez de utilizar o próprio sistema do governo, com seus ministérios, no qual seria mais acessível o controle do comportamento dos reguladores. Ainda segundo o autor, isso ocorre devido aos ganhos, por parte do governo, ocasionados por essa independência regulatória, como os de informações, flexibilidade administrativa, possibilidade de transferência de responsabilidades do governo para as agências, credibilidade por serem agências independentes e crédito pela iniciativa política.

A ANS, frente a isso, necessita estar presente e utilizar-se de mecanismos que façam valer seus processos de regulação e de "regulação da regulação", ou seja, a regulação da auto-regulação operativa pela ANS, para que efetivamente se conquiste espaço dentro dos conflitos de interesses do setor de saúde suplementar (CECÍLIO et al., 2005).

Conforme as suas atribuições legais na Lei no 9.961/00, a agência deve não somente monitorar, como agir em prol do saneamento econômico e financeiro das operadoras, garantindo os direitos dos consumidores e serviços de relevância pública. E pode lançar mão de ferramentas como a determinação de um plano de recuperação da operadora, instaurar regime de direção fiscal ou técnica, determinar a alienação da carteira de clientes e determinar a liquidação extrajudicial da operadora (CREMESP/IDEC, 2007).

\section{Considerações finais}

Este artigo procurou contextualizar a saúde suplementar no Brasil, bem como a estruturação e a regulação deste setor. Visto que a construção de um sistema de saúde suplementar acarretou muitos anos e disputas entre os diferentes setores, o 
avanço ocorreu ao longo de muitos anos e culminou na criação da Agência Nacional de Saúde Suplementar (ANS) e sua posterior implementação.

Com o número de beneficiários ultrapassando os 40 milhões, a ANS é uma realidade e uma necessidade no setor no Brasil. A ANS possui excelentes possibilidades com a criação, verificação e divulgação de indicadores da qualidade da promoção e dos cuidados integrais da saúde, e a busca pela qualificação das operadoras de seguros de saúde impulsiona a regulação. Entretanto, há também a necessidade de que a ANS amplie seu rol de atuação a todos os tipos de contratos de planos de saúde, principalmente aos contratos coletivos, a maioria dos existentes atualmente no país, para que os funcionários e empresários gozem de todas as prerrogativas da legislação do Código de Defesa do Consumidor, uma vez que a Lei no 9.656/98 e a normas da ANS não contemplam este tipo de contratação.

Por outro lado, há necessidade premente de que a ANS atue mais diretamente nas relações conturbadas entre as operadoras de planos de saúde, prestadores de serviços e beneficiários, mediando as tensões e contribuindo ativamente para a melhoria do sistema de saúde como um todo.

\section{Referências}

ACIOLI, G.G. A saúde no Brasil: cartografias do público e do privado. São Paulo: Hucitec, 2006. AGÊNCIA NACIONAL DE SAÚDE SUPLEMENTAR. Dispõe sobre a definição, a segmentação e a clasificação das operadoras de planos de assistência à saúde. Resolução da Diretoria Colegiada (RDC) de n. 39 de 30 de outubro de 2000. Disponível em: <http://www.ans.gov.br/portal/site/ legislacao/legislacao_integra.asp?id=159\&id_original=0 >. Acesso em: 27 abr. 2007.

. Caderno de Informaçôes da Saúde Suplementar: beneficiários, operadoras e planos. Ano 1 (setembro 2006), Rio de Janeiro: ANS. 2006.

. Caderno de Informaçôes da Saúde Suplementar: beneficiários, operadoras e planos. Ano 1 (junho 2007), Rio de Janeiro: ANS. 2007.

. Caderno de Informaçôes da Saúde Suplementar: beneficiários, operadoras e planos. Ano 1 (março 2007), Rio de Janeiro: ANS. 2007.

. Caderno de Informaçôes da Saúde Suplementar: beneficiários, operadoras e planos. Ano 1 (junho 2008), Rio de Janeiro: ANS. 2008.

. Programa de qualificação da saúde suplementar. Rio de Janeiro: ANS, 2005.

BAHIA, L. Planos e Seguros Saúde: padrões e mudanças das relações entre o público e o privado no Brasil. Tese (Doutorado em Saúde Pública) - ENSP/FIOCRUZ, Rio de Janeiro, 1999. 
. O mercado de planos e seguros de saúde no Brasil: tendências pós-regulação. In: NEGRI, B.; DI GIOVANNI, G. Brasil: radiografia da saúde. Campinas: UNESP, 2001. p. 325-361.

BAHIA, L.; VIANA. A. Breve histórico do mercado de planos de saúde no Brasil. In: BRASIL. Ministério da Saúde. Regulação e saúde: estrutura, evolução e perspectivas da assistência médica suplementar. Rio de Janeiro: ANS, 2002.

BRASIL. Lei no 9.656. Dispõe sobre os Planos de Assistência à Saúde. Brasília, 1998.

BRASIL. Lei n. 9 9.961/2000. Dispõe sobre a criação da ANS. Brasília, 2000(a).

BRASIL. Resoluções CONSU. Brasília, 2000(b).

BRASIL. Ministério do Trabalho e Emprego. Normas Regulamentadoras de Segurança e Saúde do Trabalhador. Brasília, 2005.

BRASIL. O impacto da regulamentação no setor de saúde suplementar / Ministério da Saúde, Agência Nacional de Saúde Suplementar - Rio de Janeiro: ANS, n. 1, 2001.

BRASIL. Ministério da Saúde, Agência Nacional de Saúde Suplementar. Integração do setor de saúde suplementar ao sistema de saúde brasileiro. Rio de Janeiro: ANS, n.2, 2001.

BRASIL. Ministério da Saúde. Agência Nacional de Saúde Suplementar. Regulação e saúde: estrutura, evolução e perspectiva da assistência médica suplementar. Rio de Janeiro: ANS, 2002.

BRASIL. Ministério da Saúde. Agência Nacional de Saúde Suplementar. Evolução e desafios da regulação do setor de saúde suplementar Rio de Janeiro: ANS, n. 4, 2003.

BRASIL. Ministério da Saúde. Agência Nacional de Saúde Suplementar. Sistema de Informaçôes de Beneficiários da ANS. Rio de Janeiro, mar/dez 2004.

BRASIL. Ministério da Saúde. Conselho Nacional de Secretários de Saúde. Saúde Suplementar. Brasília: CONASS, 2007.

BRASIL. Ministério da Saúde. Conselho Nacional de Secretários de Saúde. Regulação em Saúde. Brasília: CONASS, 2007.

CARVALHO, E. B.; CECÍLIO, L. C. de O. A regulamentação do setor saúde suplementar no Brasil: a reconstrução de uma história de disputas. Cadernos de Saúde Pública,v.23, n.9, p. 2167-2177, set. 2007.

CECÍLIO, L. C. de O. et al. A saúde suplementar na perspectiva da microrregulação. In: MS/ANS. Duas faces da mesma moeda: microrregulação e modelos assistenciais em saúde suplementar. Rio de Janeiro: ANS, 2005. p. 63-74.

CONSELHO REGIONAL DE MEDICINA DO ESTADO DE SÃO PAULO. Planos de saúde: nove anos após a Lei 9.656/98. São Paulo: CREMESP/IDEC, 2007.

DUARTE, M.C.R. A assistência suplementar no Brasil: história e características da cooperativa de trabalho Unimed In: NEGRI, B.; GIOVANNI, G. Brasil: radiografia da saúde. Campinas: Unicamp, 2001. p. 363-393. 
IBGE. Pesquisa Nacional de Amostra de Domicílios: Acesso e utilização dos serviços de saúde 1998. Rio de Janeiro: Ministério da SAÚDE/IBGE, 2000.

IBGE. Pesquisa Nacional de Amostra de Domicílios: Acesso e utilização dos serviços de saúde 2003. Rio de Janeiro: Ministério da Saúde/IBGE, 2005.

INSTITTUO BRASILEIRO DE DEFESA DO CONSUMIDOR. Planos de Saúde: nove anos após a Lei 9.656/96. São Paulo: CREMESP/IDEC, 2007.

LIMA, C. R. M. A regulação e a fiscalização do consumo de saúde suplementar no Brasil. Disponível em: http://www.ans.gov.br/portal/site/biblioteca/trabalhos_tecnicos_05.asp. Acesso em: mar. 2007. LIMA, C.R.M. Informação e regulação da assistência suplementar à saúde. Rio de Janeiro: E-Papers Serviços Editoriais, 2005.

MALTA, D.C. et al. Perspectivas da regulação na saúde suplementar diante dos modelos assistenciais. Ciênc. saúde coletiva. Rio de Janeiro, v. 9, n. 2, abr./jun. 2004.

PEREIRA, C. O marco regulatório no setor saúde suplementar: contextualização e perspectivas. Formulação de políticas para o setor de saúde suplementar no Brasil. Disponível em: www.ans.gov.br/ portal/site/biblioteca/biblioteca.asp. Acesso em: mar. 2007.

REIS, C.O.O. Os desafios da ANS frente à concentração dos planos de saúde. Revista Ciência e Saúde Coletiva, v. 12, n. 4, p. 1.041-1.050, 2007.

RONCALLI, A.G. O desenvolvimento das políticas públicas de saúde no Brasil e a construção do Sistema Único de Saúde. In: PEREIRA, A. C. (org.). Odontologia em saúde coletiva: planejando açôes e promovendo saúde. Porto Alegre: Artmed, 2003. p. 28-49.

SALAZAR, A.L.; RODRIGUES, K.; NUNES JÚNIOR, V.S. Assistência privada à saúde: regulamentação, posição do IDEC e reflexos no sistema público. In: BRASIL/MS. Direito sanitário e saúde pública, v. 1, 2005.

SCAFF, A. Regulação em saúde suplementar e os modelos de atenção à saúde. Encontro ANS-Operadoras. Florianópolis. Disponível em: www.ans.gov.br. Acesso em: mai. 2007.

SILVA, A. A. Relação entre operadoras de planos de saúde e prestadores de serviços: um novo relacionamento estratégico. Porto Alegre. 2003. Disponível em: http://www.ans.gov.br/portal/ site/Biblioteca/biblioteca_topico_17704.asp Acesso em: jan. 2007. 
Abstract

Suplemental health in Brazil: the role of the National Agency of Suplemental Health in the sector's regulation

This paper aimed to contextualize the Supplemental Health in Brazil, as well as the organization and regulation of this sector, based on literature analysis and on a critical view of the subject. The construction of a supplemental health system took many years and disputes among the several sectors, and the progress came after many years, culminating with the creation of the National Agency of Supplemental Health (ANS) and its later implementation. ANS was in charge of defending the public interest in the supplemental health care and to regulate the sectorial operators, also in their relations with services rendering and consumers, helping develop health actions. Since the number of beneficiaries exceeds 40 million people, the National Agency of Supplemental Health is a reality and a necessity for the Brazilian health sector. ANS's possibilities are excellent with the creation, verification and spreading of quality, promotion and integral health care indicators, and the search for operators' qualification stimulates regulation. On the other hand, it is needed that ANS acts more directly in the confusing relations among health plans operators, services rendering and beneficiaries, mediating tensions and contributing to the improvement of health care system as a whole.

Key words: supplemental health, ANS, regulation. 